\title{
Heavy Chain of Cytoplasmic Dynein is a Major Component of the Postsynaptic Density Fraction
}

\author{
Huei-Hsuan Cheng, ${ }^{1}$ Szu-Heng Liu, ${ }^{1}$ Hui-Cheng Lee, ${ }^{1}$ Ya-Shiuan Lin, ${ }^{2}$ \\ Zu-Han Huang, ${ }^{1}$ Cheng-I Hsu, ${ }^{1}$ Yu-Chie Chen, ${ }^{2}$ and Yen-Chung Chang ${ }^{1 \star}$ \\ ${ }^{1}$ Department of Life Science, National Tsing Hua University, Hsinchu, Taiwan, Republic of China \\ ${ }^{2}$ Department of Applied Chemistry, National Chiao-Tung University, Hsinchu, Taiwan, \\ Republic of China
}

A protein with an apparent molecular size of $490 \mathrm{kDa}$ was found in the postsynaptic density (PSD) fraction isolated from porcine cerebral cortices and rat forebrains, and this $490 \mathrm{kDa}$ protein accounted for $\sim 3 \%$ of the total protein of these samples. Matrix-assisted laser desorption ionization-time of flight mass spectrometric and Western blotting analyses consistently indicated that this $490 \mathrm{kDa}$ protein consisted primarily of the heavy chain of cytoplasmic dynein (cDHC). Immunocytochemical analyses showed that $\mathrm{CDHC}$ was found in $92 \%$ and $89 \%$ of the phalloidin-positive protrusions that were themselves associated with discrete clusters of synaptophysin, a presynaptic terminal marker, and PSD-95, a postsynaptic marker, on neuronal processes, respectively. Quantitative Western blotting analyses of various subcellular fractions isolated from porcine cerebral cortices and rat forebrains further showed that not only the heavy but also the intermediate chains of dynein are enriched in the PSD fraction. Cytoplasmic dynein is a microtubule-associated motor protein complex that drives the movement of various cargos toward the minus ends of microtubules and plays many other diverse functions in the cell. Our results that $\mathrm{CDHC}$ is a major component of the PSD fraction, that both dynein heavy and intermediate chains are enriched in the PSD fraction and that $\mathrm{CDHC}$ is present in dendritic spines raise the possibilities that cytoplasmic dynein may play structural and functional roles in the postsynaptic terminal. (c) 2006 Wiley-Liss, Inc.

Key words: MALDI-TOF; subcellular fractions; dendritic spines

Postsynaptic density (PSD) is a layer of densely packed protein complex lying underneath the postsynaptic membrane of asymmetric synapses in the mammalian central nervous system. Under electron microscopy, the PSD appears as a planar array of granular material with filaments embedded in and extending from it (Peters et al., 1991). The morphology and protein composition of the PSD in the brain have been reported to undergo activity-dependent alterations (Toni et al., 1999; Luscher et al., 2000; Dosemeci et al., 2001; Marrs et al., 2001;
Murthy et al., 2001; Toni et al., 2001; Ehlers, 2003). Accumulating evidence has suggested that the PSD plays important roles in the clustering of neurotransmitter receptors in the postsynaptic membrane, in synaptic signaling and in joining pre- and postsynaptic components together into an integrated synaptic unit (Siekevitz, 1985; Lisman and Harris, 1993; Edwards, 1995; Ziff, 1997; Kennedy, 2000; Lisman et al., 2002).

Biochemical analyses have shown that the PSD fraction isolated from brain tissues consists of four major proteins, i.e., actin, $\alpha$-subunit of calcium, calmodulindependent protein kinase II and $\alpha, \beta$-tubulin subunits, and hundreds of minor proteins, including neurotransmitter receptors, intracellular signaling molecules, cell junction proteins and scaffold proteins (Walsh and Kuruc, 1992; Kennedy, 1997; Lai et al., 1999; Walikonis et al., 2000; Sui et al., 2000; Satoh et al., 2002; Peng et al.,2004; Li et al., 2004; Yoshimura et al., 2004; Jordan et al., 2004). Studies have indicated that many proteins in the PSD are arranged in a laminar fashion between its surface facing the postsynaptic membrane and that facing the cytoplasm of dendritic spines (Valtschanoff and Weinberg, 2001; Peterson et al., 2003). The core of the PSD has been proposed to consist of a variety of scaffold proteins that link neurotransmitter receptors and cell adhesion molecules residing on the postsynaptic membrane to various intracellular signaling molecules and microfilament cytoskeleton residing in the cytoplasm of dendritic spines (Ziff, 1997; Kennedy, 2000; Sheng and Sala, 2001; Baron et al., 2006).

Contract grant sponsor: National Science Council; Contract grant number: 91WFA0400454; Contract grant sponsor: Ministry of Economic Affairs; Contract grant number: 91-EC-17A-17S1-0009.

*Correspondence to: Yen-Chung Chang, Department of Life Science, National Tsing Hua University, Hsinchu, Taiwan.

E-mail: ycchang@life.nthu.edu.tw

Received 29 December 2005; Revised 24 March 2006; Accepted 3 April 2006

Published online 23 May 2006 in Wiley InterScience (www. interscience.wiley.com). DOI: 10.1002/jnr.20898 
By using a SDS-PAGE (sodium dodecylsulfate polyacrylamide gel electrophoresis) procedure suitable for analyzing large proteins (Weber and Osborn, 1969), we found that the heavy chain of cytoplasmic dynein (cDHC) was also a major protein constituent of PSD fraction isolated from both porcine cerebral cortices and rat forebrains. Fluorescence immunocytochemical studies of cultured rat cortical neurons showed the presence of cDHC immunoreactivity in most of the spines that were associated with synaptophysin-positive and PSD-95-positive accumulations on the processes. Western blotting analysis of various subcellular fractions isolated from porcine cerebral cortices and rat forebrains indicated that both the heavy and intermediate chains of cytoplasmic dynein were enriched in the PSD fraction. Cytoplasmic dynein is a microtubule-associated motor protein that plays diverse functions in the cell (Holleran et al., 1998; Dujardin and Vallee, 2002; Nedelec et al., 2003). The possible roles of dynein subunits in the postsynaptic terminal are discussed.

\section{MATERIALS AND METHODS}

\section{Isolation of PSD and Other Sub-Cellular Fractions From Pig Cerebral Cortices and Rat Forebrains}

Brain homogenates, PSD and other sub-cellular fractions (including crude membrane, synaptic plasma membrane, synaptic junction, microsome, cytosol, mitochondria, and myelin sheath) were prepared from porcine cerebral cortices and rat forebrains by a method published previously (Lai et al., 1998). In brief, brain tissues were first suspended with 6 vol of Buffer A (0.1 mM EDTA, $0.1 \mathrm{mM}$ EGTA, and $1 \mathrm{mM}$ HEPES at $\mathrm{pH}$ 7.4) containing $0.32 \mathrm{M}$ sucrose and homogenized by a Polytron (Brinkmann) at a setting of 6 for $30 \mathrm{sec}$. The homogenate was centrifuged at $4,420 \times g$ for $5 \mathrm{~min}$, and the supernatant was saved and kept on ice. The resultant pellet was suspended in $4 \mathrm{vol}$ of the same sucrose solution and centrifuged again at $4,420 \times g$ for $5 \mathrm{~min}$. The combined supernatants were then centrifuged at $38,900 \times g$ for $45 \mathrm{~min}$. The resultant supernatant was further centrifuged at $245,000 \times g$ for $1 \mathrm{hr}$ at $4^{\circ} \mathrm{C}$ to pellet microsomal membranes. The pellet obtained after the $38,900 \times g$ centrifugation step was suspended in 2 vol of $2 \mathrm{mM}$ Tris-acetate at $\mathrm{pH} 8.1$ and applied on the top of Buffer A containing $1.2 \mathrm{M}$ sucrose. After centrifugation at $245,000 \times g$ for $50 \mathrm{~min}$, the pellet was saved and used in this study as the mitochondria fraction, whereas the white material in the interface was collected for further purification of synaptic plasma membranes. The collected white material was applied on top of Buffer A containing $0.9 \mathrm{M}$ sucrose. After centrifugation at $245,000 \times g$ for $50 \mathrm{~min}$, the white membranous material in the interface was collected and used as the myelin fraction in this study, and the pellet was the synaptic plasma membrane fraction. Synaptic junctions were then isolated from synaptic plasma membranes by the procedures of Chang et al. (1991), and from the synaptic junction the PSD fraction was prepared by the procedures of Cohen et al. (1977). In brief, synaptic junctions were diluted to $4 \mathrm{mg}$ of protein/ml by Buffer $\mathrm{B}\left(50 \mu \mathrm{M} \mathrm{CaCl}_{2}, 6 \mathrm{mM}\right.$ Tris$\mathrm{HCl}$ at $\mathrm{pH}$ 8.1), mixed with an equal volume of Buffer $\mathrm{C}$
(0.32 M sucrose, $1 \%$ vol/vol Triton X-100, and $12 \mathrm{mM}$ Tris$\mathrm{HCl}$ at $\mathrm{pH}$ 8.1), incubated on ice for $15 \mathrm{~min}$, and finally centrifuged at $32,800 \times g$ for $20 \mathrm{~min}$. The resulting pellet was suspended in Buffer B and applied on top of step gradients consisting of $1.0,1.5$, and $2.0 \mathrm{M}$ sucrose containing $1 \mathrm{mM}$ $\mathrm{NaHCO}_{3}$. After centrifugation at $200,000 \times g$ for $2.5 \mathrm{hr}$, the band in the interface between the 1.5 and $2.0 \mathrm{M}$ sucrose layers was collected. The collected sample was then mixed with an equal volume of a solution containing $150 \mathrm{mM} \mathrm{KCl}$ and $1 \%$ Triton X-100 and centrifuged at 200,000 $\times g$ for $20 \mathrm{~min}$. The resulting pellet was suspended in $50 \mu \mathrm{M} \mathrm{CaCl}_{2}$ and $6 \mathrm{mM}$ Tris$\mathrm{HCl}$ at $\mathrm{pH} 8.1$ and used as the PSD fraction in further experiments. Iodoacetamide $(2 \mathrm{mM})$ was added to all buffer solutions to prevent inter-protein disulfide bond formation. A protease inhibitor cocktail containing (final concentration) $1 \mu \mathrm{g} / \mathrm{ml} \mathrm{leu}-$ peptin, $1 \mu \mathrm{g} / \mathrm{ml}$ pepstatin $\mathrm{A}, 1 \mathrm{mM}$ benzamidine and $0.25 \mathrm{mM}$ PMSF was added to all buffer solutions used for the isolation. Protein concentrations were determined by the method of Lowry (1951).

\section{Electrophoresis and Western Blotting}

SDS-PAGE was carried out with a mini-gel apparatus (Mini-Protean 3; BioRad, Hercules, CA) using either 9\% polyacrylamide-gels according to the method of Laemmli (1970) or 3.5\% polyacrylamide-gels according to the method of Weber and Osborn (1969). After electrophoresis, the proteins in the gels were directly stained with Coomassie blue or transferred onto a polyvinylidene difluoride (PVDF) membrane (Millipore, Bedford, MA) for Western blotting analysis or staining with a ProtoGold protein detection kit (British BioCell International, Cardiff, UK). Western blotting was carried out as described previously (Wu et al., 1996). The polyclonal antibodies to cDHC (Dynein R-325), PSD-95 (C-20), and an E. coli-expressed $63 \mathrm{kDa}$ tagged fusion protein (sc4382) corresponding to amino acids 4320-4644 of dynein heavy chain of human origin were purchased from Santa Cruz Biotechnology (Santa Cruz, CA). The monoclonal mouse anti-chick cDIC, anti-synaptophysin and anti-syntaxin antibodies were obtained from Sigma (St. Louis, MO). Horse radish peroxidase-conjugated secondary antibodies were purchased from Chemicon (Temecula, CA). An enhanced chemiluminescence (ECL) kit was obtained from Pierce (Rockford, IL). The ECL-film was purchased from Amersham Pharmacia Biotech (Little Chalfont, UK). The molecular size markers used in this study included cross-linked phosphorylase b (Sigma) and high range SDS-PAGE standards (Bio-Rad). The relative intensity of Coomassie blue-stained and immunostained bands was quantified using the Total Lab image analysis software system (Nonlinear Dynamics, Newcastle, UK).

\section{Electroelution of the $490 \mathrm{kDa}$ Protein}

The $490 \mathrm{kDa}$ protein of the PSD was electroeluted from the polyacrylamide gels by the procedures of Chang and Gottlieb (1988). Briefly, the PSD was first denatured by incubating with SDS (1\%) in a boiling water bath for $5 \mathrm{~min}$ and then treated sequentially with dithioerythritol and iodoacetamide under nitrogen. The carbamidomethylated PSD proteins were then separated by a $3.5 \%$ polyacrylamide gel according to the 


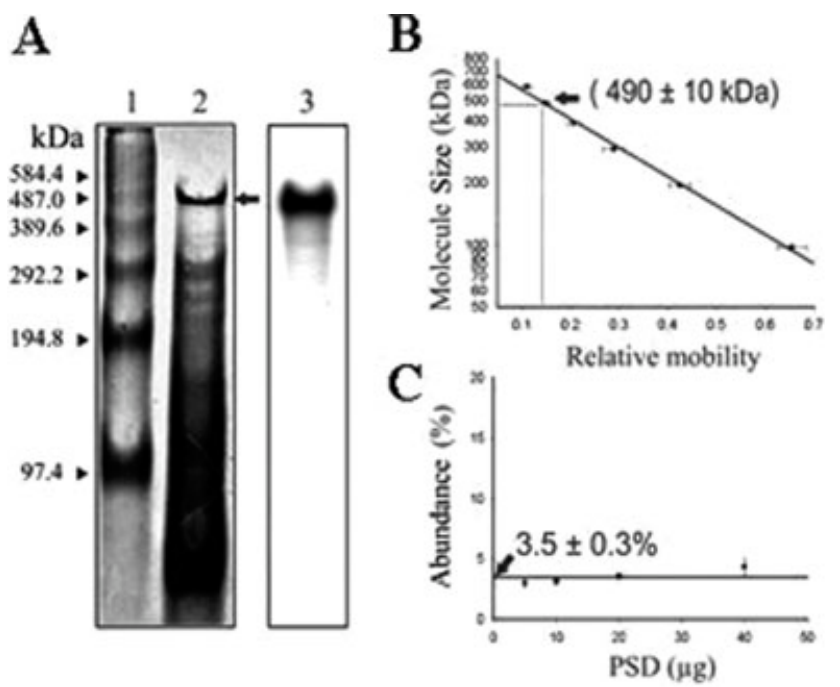

Fig. 1. Detection of a $490 \mathrm{kDa}$ protein in the PSD. A: SDS-PAGE and Western blotting analyses of the PSD isolated from porcine cerebral cortices. Chemically cross-linked phosphorylase b $(6 \mu \mathrm{g}$, lane $\mathbf{1}$, sizes as indicated to the left) and porcine PSD proteins $(30 \mu \mathrm{g}$ in lane 2, $10 \mu \mathrm{g}$ in lane 3) were separated using 3.5\% SDS-gels according to the procedures reported by Weber and Osborn (1969). Proteins in the resultant gels were stained with Coomassie blue (lane 2) or transferred to PVDF membrane and probed with rabbit anti-rat $\mathrm{cDHC}$ antibody (lane 3). Arrow indicated a major protein near the top of the gel (lane 2) that was recognized by the rabbit anti-rat cDHC antibody (lane 3). B: Determination of the molecular size of the arrow-indicated band in lane 2 of (A) by a calibration curve constructed by plotting the logarithm of the molecular sizes of chemi-

method of Weber and Osborn (1969). The $490 \mathrm{kDa}$ protein band was visualized by staining the resultant gel with Coomassie blue, and the band was finally cut out of the gel. The gel pieces were transferred to an electroelutor (Little Blue Tank, Isco, Inc., Lincoln, NE). The electro-elution was carried out following the procedures provided by the manufacturer.

\section{Matrix-Assisted Laser Desorption Ionization-Time of Flight Mass Spectrometric Analysis and Peptide Mass Fingerprinting}

The PSD proteins were separated by a $3.5 \%$ polyacrylamide gel according to the method of Weber and Osborn (1969). The $490 \mathrm{kDa}$ protein was visualized after staining the gel with Coomassie blue and then excised. A piece of gel in the region next to where the $490 \mathrm{kDa}$ protein appeared, but not containing any proteins, was also excised and used as the control sample. These gel pieces were subject to in-gel digestion with trypsin (Promega, Madison, WI) according to the procedure published previously (Shevchenko et al., 1996). The resultant tryptic peptides were extracted from gel pieces and subjected to matrix-assisted laser desorption ionizationtime of flight (MALDI-TOF) mass spectrometry analysis using a BiFlex III MALDI-TOF MS (Bruker Daltonics, Leipzig, Germany). The results were compared against the database
D E

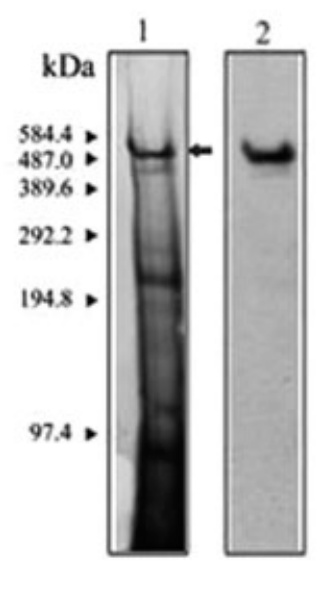

cally cross-linked phosphorylase $\mathrm{b}$ against the relative mobility. The correlation coefficient is -0.997 . Data are means \pm SD of four experiments. The apparent size of this protein band was determined to be $490 \pm 10 \mathrm{kDa}$. C: Determination of the abundance of the 490 $\mathrm{kDa}$ protein in the PSD. PSD $(5,10,20$, and $40 \mu \mathrm{g})$ was subjected to SDS-PAGE analysis. The abundance of the $490 \mathrm{kDa}$-protein was quantified from the densitometric scans of the resultant Coomassie blue-stained SDS-gels to be $3.5 \pm 0.3 \%$. Data are means \pm SD of three experiments. D-F: The PSD isolated from rat forebrains were subject to the same analysis under identical conditions to that described above in (A-C), respectively, except for not showing the Coomassie blue-stained pattern of chemically cross-linked phosphorylase $\mathrm{b}$ markers.

NCBInr.10.21.2003 using MS-Fit using the following conditions of search: species: mammals; proteins molecular weight: 250-600 kDa; full pI range; hydrogen at the $\mathrm{N}$ terminus and free acid at the $\mathrm{C}$ terminus; cysteine residues modified by carbamidomethylation; maximum number of missed cleavages: 3; peptide mass tolerance: $0.3 \mathrm{Da}$.

\section{Cortical Cell Culture}

Cells were dissociated from the fetus of Sprague-Dawley rats on Day 18 of gestation, plated on poly-1-lysine-coated glass coverslips (18 $\mathrm{mm}$ in diameter) and maintained in serum-free medium following the procedures reported by Brewer et al. (1993).

\section{Fluorescence Immunocytochemistry}

For double fluorescence immunolabeling of neurons, cultured rat cortical neurons were washed three times with PBS (phosphate buffered saline), incubated with fixation solution $(3.75 \%$ paraformaldehyde, $0.25 \%$ glutaraldehyde, and $4 \%$ sucrose in $\mathrm{PBS}$ ) at $37^{\circ} \mathrm{C}$ for $25 \mathrm{~min}$, and then permeabilized by treatment with $0.05 \%$ Triton X-100 in PBS at room temperature for $15 \mathrm{~min}$. Afterwards, the cells were incubated with $3 \%$ normal goat serum at room temperature for $45 \mathrm{~min}$ and then with mouse anti-synaptophysin antibody $(1 \mu \mathrm{g} / \mathrm{ml}$ PBS) 
and rabbit anti-cDHC antibody $(1 \mu \mathrm{g} / \mathrm{ml} \mathrm{PBS})$ or with mouse anti-PSD-95 antibody $(1 \mu \mathrm{g} / \mathrm{ml} \mathrm{PBS})$ and rabbit anti-cDHC antibody $(1 \mu \mathrm{g} / \mathrm{ml} \mathrm{PBS})$ at $4{ }^{\circ} \mathrm{C}$ overnight. The cells were incubated with Cy5-conjugated goat anti-rabbit $\operatorname{IgG}(5 \mu \mathrm{g} /$ ml) (Molecular Probes, Eugene, OR) and FITC-conjugated goat anti-mouse $\operatorname{IgG}(5 \mu \mathrm{g} / \mathrm{ml})$ (Santa Cruz) at $37^{\circ} \mathrm{C}$ for 1.5 hr. Subsequently, the cells were incubated with Alexa Fluro 546 phalloidin $(50 \mathrm{U} / \mathrm{ml})$ (Molecular Probes) at room temperature for $1 \mathrm{hr}$. After washing with PBS, the cells were sealed with Prolong Antifade (Molecular Probes) and examined using a confocal microscope (LSM 5 PASCAL, Zeiss). For quantitative analyses, a spine was defined as a phalloidin-positive protrusion $<6 \mu \mathrm{m}$ in length on a process of a pyramidal-shaped neuron. Synaptophysin- and PSD-95-positive accumulations with diameters $>1 \mu \mathrm{m}$ were taken into analysis.

\section{RESULTS}

\section{Biochemical Identification of Cytoplasmic Dynein Heavy Chain in the PSD Fraction}

The PSD fraction isolated from porcine cerebral cortices was subject to SDS-PAGE analyses using 3.5\% polyacrylamide gels according to the procedures reported by Weber and Osborn (1969). After Coomassie bluestaining, the resultant gel (Fig. 1A, lane 2) showed an intensely stained protein band (indicated by arrow) with an apparent size of $490 \pm 10 \mathrm{kDa}(n=4)$, as calculated from a calibration curve constructed by the relative mobility of cross-linked phosphorylase b markers (Fig. 1A, lane 1) run in the same gel (Fig. 1B). Varied amounts of the PSD were subject to SDS-PAGE analysis by the same procedures, and quantitative analyses of the resultant Coomassie blue-stained gels indicated that this 490 $\mathrm{kDa}$ protein accounted for $3.5 \pm 0.3 \%(n=3)$ of the total porcine PSD protein (Fig. 1C). Similar to the porcine PSD, SDS-PAGE analysis of the PSD fraction isolated from rat forebrains also showed a protein (Fig. 1D, lane 1) with an apparent size of $490 \pm 20 \mathrm{kDa}$ (means $\pm \mathrm{SD}, n=3$; Fig. $1 \mathrm{E}$ ), and this $490 \mathrm{kDa}$ protein was found to account for $2.4 \pm 0.5 \%(n=3)$ of the total rat PSD protein (Fig. 1F). Due to the fact that proteins smaller than $35 \mathrm{kDa}$ migrated off from the $3.5 \%$ gels used for the above analyses, the abundance of the 490 $\mathrm{kDa}$ protein in the porcine and rat PSD fractions may be slightly lower than the above estimations.

Western blotting analysis of the porcine and rat PSD with a polyclonal rabbit anti-rat cDHC (heavy chain of cytoplasmic dynein) antibody (epitope corresponding to the amino acid residues 4320-4644 fragment of rat $\mathrm{CDHC}$ ) showed an intensely immunostained band of the same size as the $490 \mathrm{kDa}$ protein found in the Coomassie blue-stained gels (Fig. 1A, lane 3; Fig. 1D, lane 2). To confirm that the $490 \mathrm{kDa}$ protein in the PSD indeed contained a CDHC-like sequence that was recognized by the rabbit anti-rat $\mathrm{CDHC}$ antibody in the above analyses, we isolated the $490 \mathrm{kDa}$ protein from the porcine PSD by electro-elution and tested if the isolated $490 \mathrm{kDa}$ protein could interfere with the immunoreaction between anti-cDHC antibody and its antigen
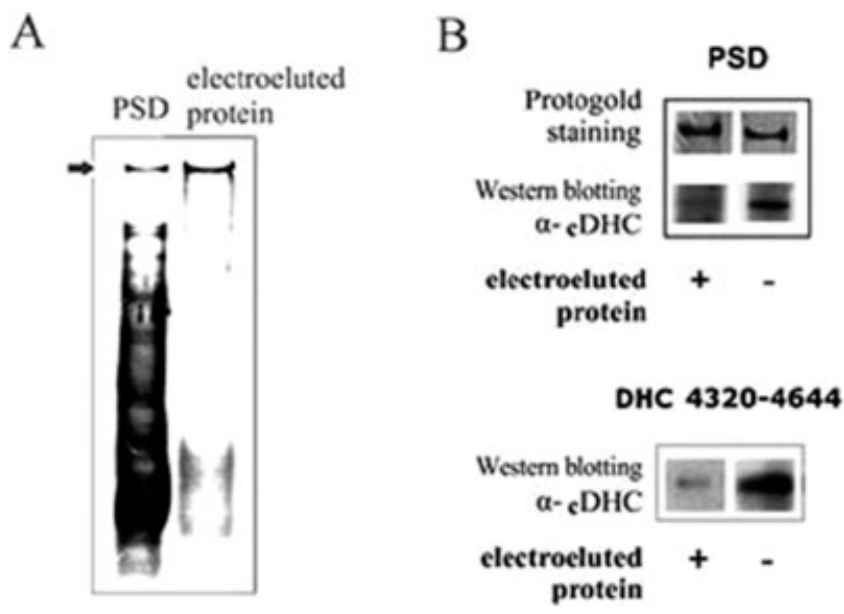

Fig. 2. Inhibition of the immunoreaction between the antibody to cDHC and its antigen peptide by the $490 \mathrm{kDa}$-protein of the PSD. A: SDS-PAGE analysis of the porcine PSD ( $3 \mu \mathrm{g}$ protein, left lane) and the $490 \mathrm{kDa}$ protein $(0.1 \mu \mathrm{g}$ protein, right lane) isolated from porcine PSD by electroelution. Arrow indicated the $490 \mathrm{kDa}$ protein band. B: Upper panel: PSD proteins $(5 \mu \mathrm{g})$ were separated with a $3.5 \%$ SDS-gel according to the procedures of Weber and Osborn (1969), electro-transferred to PVDF membrane and then probed with the rabbit anti-rat cDHC antibody that had not $(-)$ or had $(+)$ been incubated with the electroeluted $490 \mathrm{kDa}$ protein (final concentration $=$ $1.25 \mu \mathrm{g} / \mathrm{ml}$ ) at $4^{\circ} \mathrm{C}$ overnight (bottom lanes). The blot was then stripped and stained with ProtoGold (top lanes). Bottom panel: A fusion protein containing rat cDHC residues 4320-4644 (that is the epitope for the anti-cDHC antibody used here) was separated by a 9\% SDS-gel according to the procedures of Laemmli (1970), transferred to a PVDF membrane, and then probed with the rabbit antirat $\mathrm{CDHC}$ antibody, which had not $(-)$ or had $(+)$ been incubated with electro-eluted $490 \mathrm{kDa}$ (final concentration $1 \mu \mathrm{g} / \mathrm{ml}$ ) at $4^{\circ} \mathrm{C}$ overnight.

(Fig. 2A, right lane). Pre-incubation of the anti-cDHC antibody $(1 / 1,500$ dilution) with the electroeluted protein $(1.25 \mu \mathrm{g} / \mathrm{ml})$ at $4^{\circ} \mathrm{C}$ overnight effectively blocked the immunoreaction between this antibody and the 490 $\mathrm{kDa}$ protein in the PSD (Fig. 2B, upper panels). This anti-cDHC antibody immunostained intensely a fusing protein containing its epitope, and this immunoreaction was also effectively blocked by pre-incubating the antibody with the electro-eluted $490 \mathrm{kDa}$ protein (Fig. 2B, lower panels). These observations indicated that the 490 $\mathrm{kDa}$ protein found during the SDS-PAGE analysis of porcine PSD fraction (Fig. 1A) is $\mathrm{CDHC}$.

\section{MALDI-TOF Mass Spectrometry Used to Identify $490 \mathrm{kDa}$ Protein in Rat Forebrain PSD Fraction}

The $490 \mathrm{kDa}$ protein was digested by trypsin, and the resultant tryptic peptides were subject to mass spectrometric analysis. The resultant spectrum (Fig. 3) showed 36 well-resolved $\mathrm{m} / \mathrm{z}$ ion peaks between the two peaks corresponding to two internal calibration markers (bradykinin, 1,060.57 Da; melittin, 2,845.76 Da). After eliminating 14 peaks that also appeared in the 


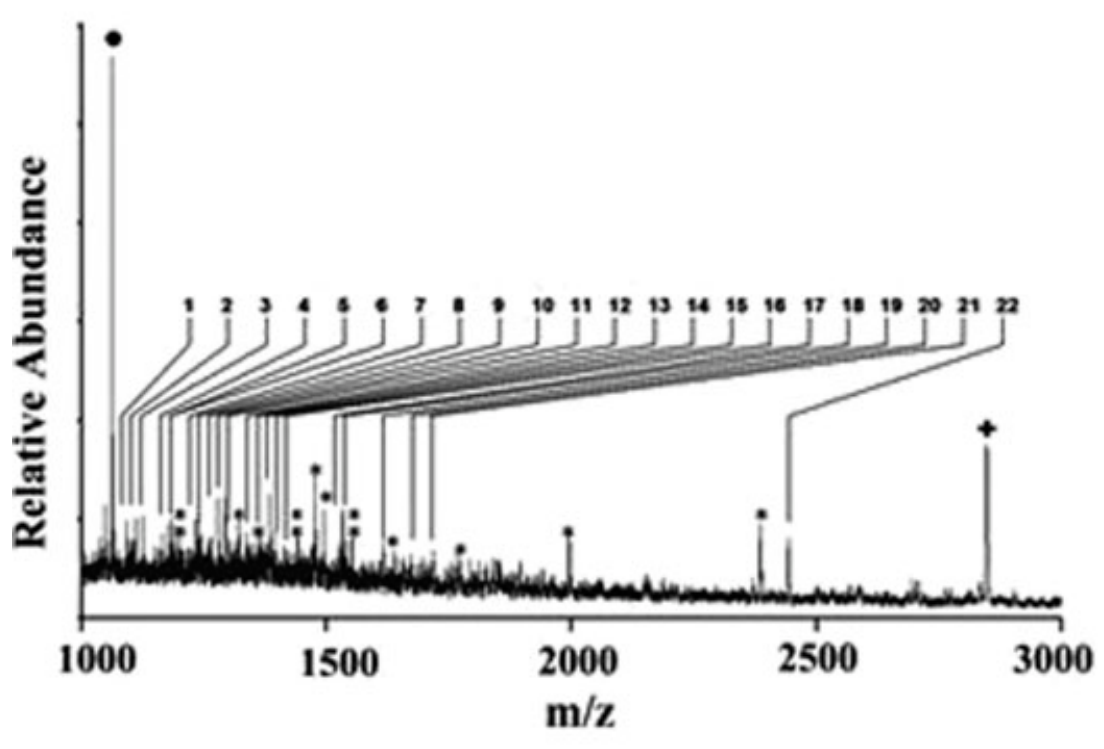

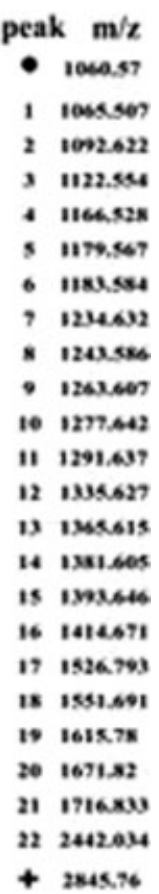

Fig. 3. MALDI-TOF mass spectrum of the peptides resulting from in-gel digestion of the $490 \mathrm{kDa}$ protein in the rat forebrain PSD with trypsin. Twentytwo peptide peaks (marked 1 22 with their mono-isotopic $\mathrm{m} / \mathrm{z}$ values listed to the right) were found after eliminating 14 peaks (marked with $*$ ) that also appeared in the control sample (the sample obtained by in-gel digesting gel pieces cut from a nearby blank region). Peaks of the internal calibration standards: bradykinin $(\bullet, 1,060.57 \mathrm{Da})$ and melittin ( $+, 2,845.76 \mathrm{Da})$. The results are from a single experiment representative of four experiments. control sample, 20 of the remaining 22 peaks (except for the $\mathrm{m} / \mathrm{z}$ peaks of $1,166.528$ and $1,335.627)$ were matched to their counterpart tryptic peptides of the rat cytoplasmic dynein heavy chain 1 . These peptides covered $6 \%$ of the rat cDHC sequence. In all of our MALDI-TOF experiments $(n=4)$, the majority of tryptic peptides from the $490 \mathrm{kDa}$ protein of the PSD could be matched to their counterparts of $\mathrm{cDHC}$. By the same analysis, the tryptic peptides of the $490 \mathrm{kDa}$ protein in the porcine PSD were also found to match their counterpart tryptic peptides of $\mathrm{cDHC}$ (data not shown). The results suggest that the $490 \mathrm{kDa}$ protein found in the porcine and rat PSD fractions consist primarily of cDHC. That $\mathrm{cDHC}$ is a constituent protein of the PSD is also supported by the study of Yoshimura et al. (2004) who detected CDHC peptides in the tryptic digests of rat forebrain PSD by 2-dimensional liquid chromatographytandem mass spectrometry.

\section{Fluorescence Immunocytochemical Studies of the Localization of cDHC in Cultured Rat Cortical Neurons}

The distribution of cDHC and other molecular markers in cultured rat cortical neurons was studied by fluorescence immunostaining means. Mature cultured neurons (at 20-24 DIV) were triply stained with the antibodies to $\mathrm{CDHC}$ and synaptophysin, a presynaptic marker (Fletcher et al., 1991), and with Alexa Fluro 546-conjugated phalloidin that stains dendritic spines intensely (colored in red, green, and purple respectively in Fig. 4). Quantitative analyses showed that $\mathrm{cDHC}$ was found in $92 \%$ (201 in 218 protrusions in 20 neurons) phalloidin-positive spines that overlapped with synaptophysin accumulations. Cultured rat cortical neurons were also triply stained with antibodies to $\mathrm{CDHC}$ (red) and to PSD-95 (green), a protein greatly enriched in the postsynaptic terminal (Cho et al., 1992), and with Alexa Fluro 546-conjugated phalloidin (purple) (Fig. 5). Quantitative analyses showed that cDHC was found in 89\% (101 in 113 protrusions in 12 neurons) of phalloidin-positive spines that overlapped with PSD-95 accumulations. These observations suggest that the $\mathrm{CDHC}$ reside in the postsynaptic terminals of most of the synapses made on dendritic spines in cultured rat cortical neurons.

\section{Western Blotting Analysis of the Distribution of Dynein Subunits in Various Subcellular Fractions Isolated From Porcine and Rat Brain Tissues}

The distribution of cDHC in various sub-cellular fractions (including PSD, crude membrane, synaptic plasma membrane, synaptic junction, microsome, cytosol, mitochondria, and myelin sheath fractions) and the homogenates prepared from porcine cerebral cortices and rat forebrains was investigated by Western blotting analysis with the polyclonal rabbit anti-rat $\mathrm{CDHC}$ antibody. Based on the intensities of immunostained bands, the PSD fraction was found to contain more cDHC than the remaining sub-cellular fractions isolated from either porcine cerebral cortex (Fig. 6A) or rat forebrains (Fig. 6B). We found that $\mathrm{CDHC}$ was enriched in the microsome fraction (Fig. 6). This finding was consistent with that cytoplasmic dynein participates in the intracellular movements of cellular organelles and with a previ- 

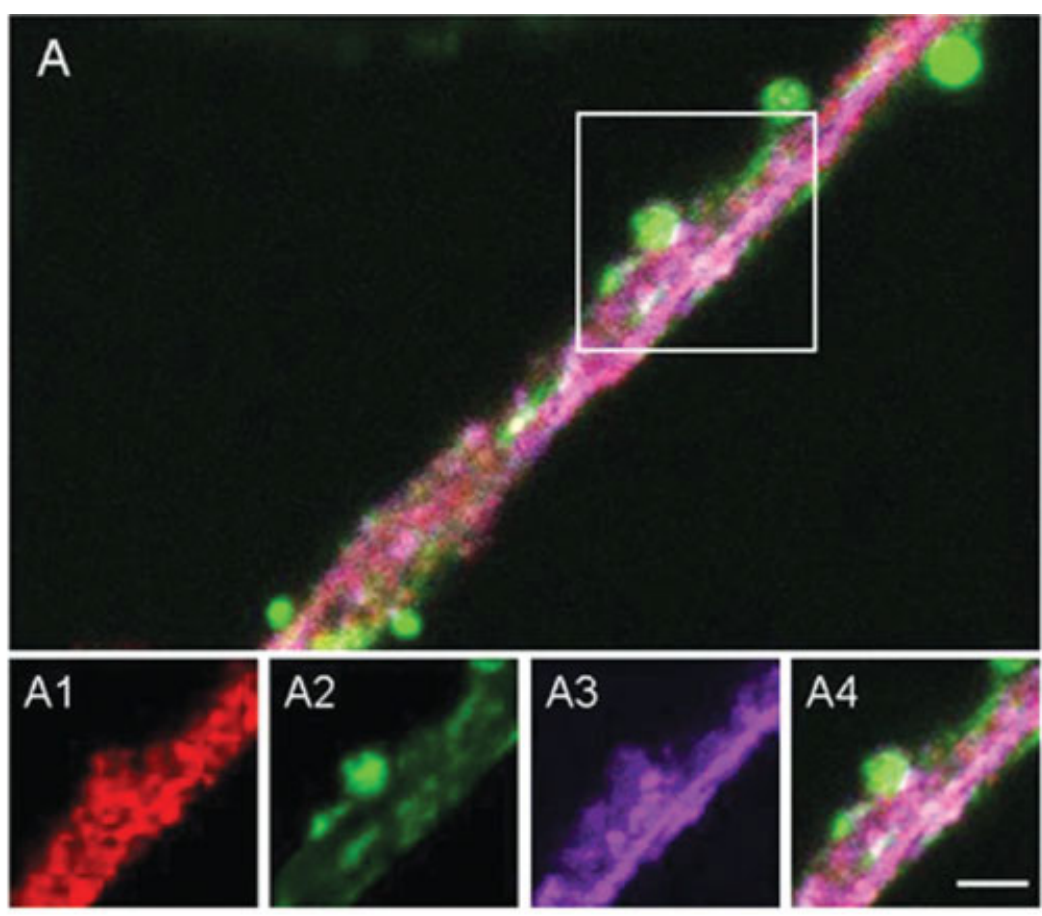

Fig. 4. cDHC was found in most of phalloidinpositive protrusions that were associated with synaptophysin-positive clusters on the processes of cultured rat cortical neurons. Cultured rat cortical neurons at 20-24 DIV were triple stained for cDHC (red), synaptophysin (green), and Factin (purple), and two processes from two different neurons are shown in (A) and (B). A1-A4 are the region enclosed by the white box in (A) visualized for $\mathrm{cDHC}$, synaptophysin, F-actin and overlay of the first three, respectively. B1-B4 are the region enclosed by the white box in (B) visualized for $\mathrm{CDHC}$, synaptophysin, F-actin, and overlay of the first three, respectively. Scale bars $=$ $3 \mu \mathrm{m}$.

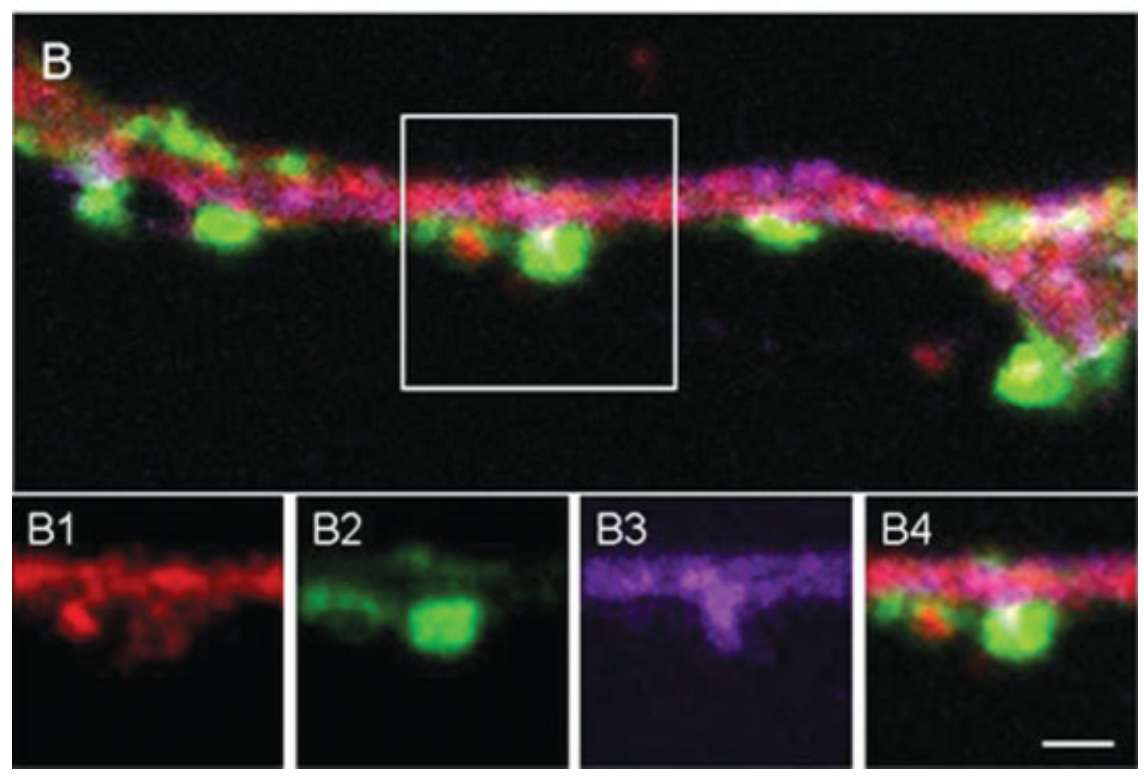

ous finding that dynein bound brain microsomes (Yu et al., 1992). Distributions of PSD-95, which were enriched in the postsynaptic terminals, and synaptophysin and syntaxin, which were enriched in the presynaptic terminals of neurons (Hata et al., 1993) in these sub-cellular fractions, were also analyzed. PSD-95 was found enriched primarily in the PSD fraction and synaptic junction fractions, whereas, in contrast, synaptophysin and syntaxin were very low (in rat samples) in and even absent (in porcine samples) from the PSD fraction and synaptic junctions (Fig. 6A,B, bottom panels).

We then investigated if the PSD fraction also contained the intermediate chain of cytoplasmic dynein (cDIC), another major component of cytoplasmic dynein. The porcine and rat PSD fractions were separated by $9 \%$ SDS-gels according to the procedures of Laemmli (1970) and then subject to Western blotting analysis with a monoclonal mouse anti-chick cDIC antibody. In the 


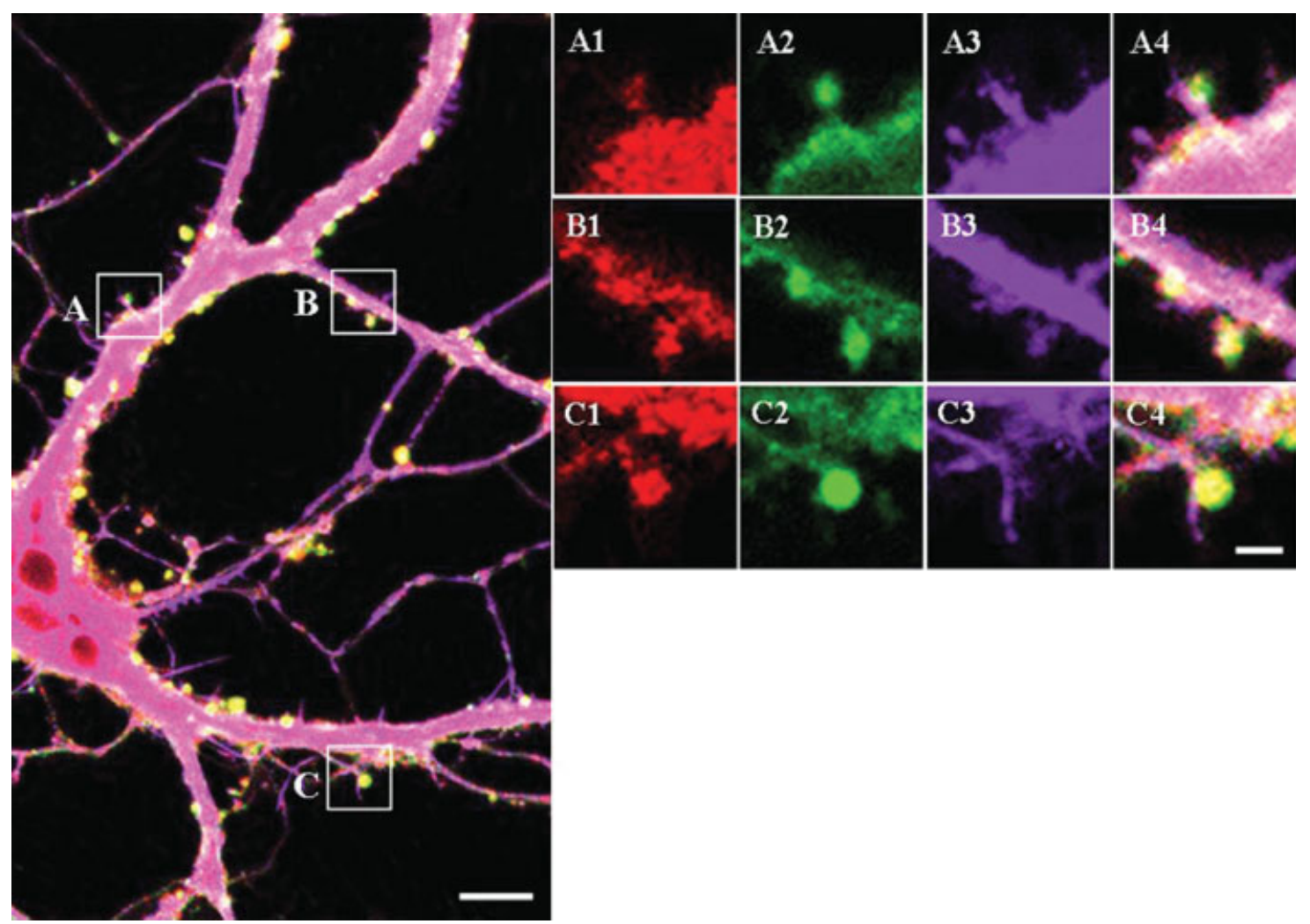

Fig. 5. cDHC was found in most of phalloidin-positive protrusions that co-localized with PSD95-positive clusters on the processes of cultured rat cortical neurons. Left: a cultured rat cortical neuron at 20-24 DIV was triple stained for CDHC (red), PSD-95 (green), and F-actin (purple). Scale bar $=10 \mu \mathrm{m}$. Three regions, labeled by A, B, and C, enclosed by white boxes in the left figure are shown at higher magnification and visualized for CDHC, PSD-95, F-actin, and overlay of the first three, respectively, as Figures A1-A4, B1-B4, and C1-C4 to the right. Scale bar in $\mathrm{C} 4=3 \mu \mathrm{m}$.

porcine cerebral PSD and rat forebrain PSD fraction, this antibody recognized a protein with a size of $75 \mathrm{kDa}$ (Fig. 7A), which is close to the reported size of cDIC, $\sim 74$ kDa (Paschal et al., 1992; Steffen et al., 1996). Western blotting analyses of the sub-cellular fractions and homogenates prepared from porcine cerebral cortices and rat forebrains indicated the enrichment of cDIC in the PSD fraction, and the cDIC content in the PSD fraction was around two-fold of that in the homogenates (Fig. 7B,C).

\section{DISCUSSION}

We reported that the heavy chain of cytoplasmic dynein accounts for $\sim 3 \%$ of the total protein of the PSD fraction isolated from porcine cerebral cortices and rat forebrains. This makes $\mathrm{CDHC}$ a major protein component of the PSD fraction with an abundance only next to $\alpha, \beta$-tubulins (12-18\%), the $\alpha$-subunit of calcium, calmodulin-dependent protein kinase $2(9-11 \%)$ and actin (4-5\%) (Lai et al., 1999; Sui et al., 2000). Furthermore, the PSD fraction contains proportionately more cDHC and cDIC than other sub-cellular fractions isolated from the same brain tissues.

Our immunocytochemical studies showed the presence of $\mathrm{cDHC}$ in the majority of dendritic spines that were associated with clusters of a presynaptic marker, synaptophysin, or with clusters of a postsynaptic marker, PSD-95, in cultured rat cortical neurons. Unlike our Western blotting results indicating that $\mathrm{CDHC}$ was enriched in the PSD fraction, cDHC immunoreactivity however was not found to be particularly higher in regions where the PSD was likely to reside, such as the head region of spines. This is probably due to that the accessibility of cDHC in the PSD to the antibody in solution is lower than that of $\mathrm{CDHC}$ in the cytoplasm because of the more compact structure of the former subcellular specialization.

Naisbitt et al. (2000) reported earlier the enrichment of an $8 \mathrm{kDa}$ dynein light chain in the PSD, and Chuang et al. (2001) reported that RP3, a $14 \mathrm{kDa}$-dynein light chain, is affiliated with the PSD. These findings and those reported here together indicate that the PSD contains at least three major subunits, the light, intermediate, and heavy chains, of cytoplasmic dynein. The $8 \mathrm{kDa}$-dynein 
Fig. 6. Distribution of cDHC, PSD-95, syntaxin and synaptophysin in subcellular fractions isolated from porcine cerebral cortices (A) and from rat forebrains (B). The subcellular fractions were isolated from porcine cerebral cortices and rat forebrains according to the procedures described in the Materials and Methods. Crude homogenate and eight sub-cellular fraction samples, each containing $10 \mu \mathrm{g}$ protein, were separated by $3.5 \%$ SDS-gels according to the procedures of Weber and Osborn (1969), electro-transferred to a PVDF membrane and then immunostained with rabbit anti-rat cDHC antibody (top panels from the top of A and B). Second panels from the top of (A) and (B): relative amounts of the immunostained bands in the blots (top panels of A and B) relative to those of the PSD fraction (means $\pm \mathrm{SD}, n=4)$. Crude homogenate and 8 sub-cellular fraction samples, each containing $10 \mu \mathrm{g}$ protein, isolated from porcine cerebral cortices and rat forebrains were separated by $9 \%$ SDS-gels by the procedures of Laemmli (1970), electrotransferred to a PVDF membrane and then immunostained respectively with antiPSD-95 (third panels from the top of $\mathbf{A}$ and $\mathbf{B}$, respectively), anti-synaptophysin antibodies (fourth panels of $\mathbf{A}$ and $\mathbf{B}$, respectively) and anti-syntaxin (bottom panels of $\mathbf{A}$ and $\mathbf{B}$, respectively). $\mathrm{BH}$, brain homogenates; SPM, synaptic plasma membrane; SJ, synaptic junction; MS, microsome; PSD, postsynaptic density; CT, cytosol; MT, mitochondria; MY, myelin sheath.
A

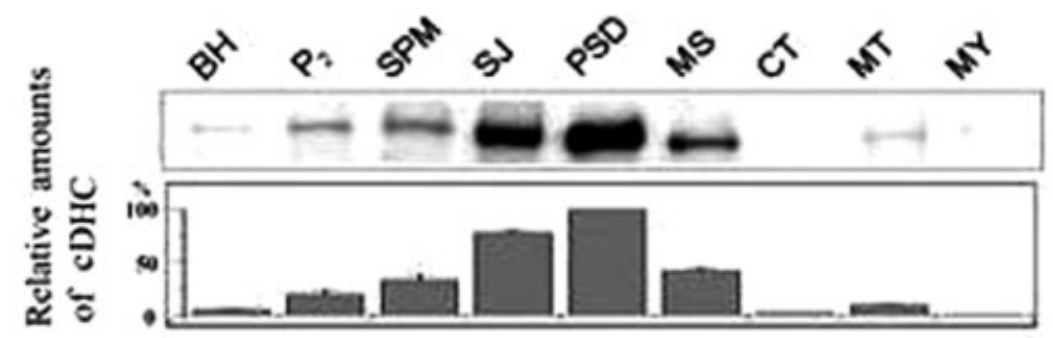

PSD 95

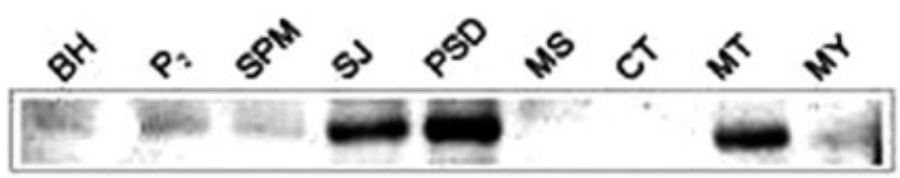

Synaptophysin

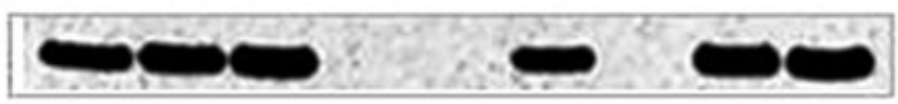

Syntaxin

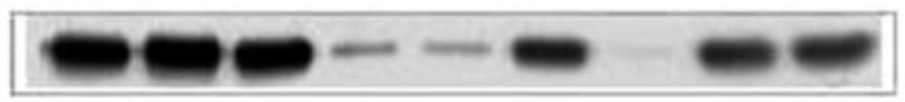

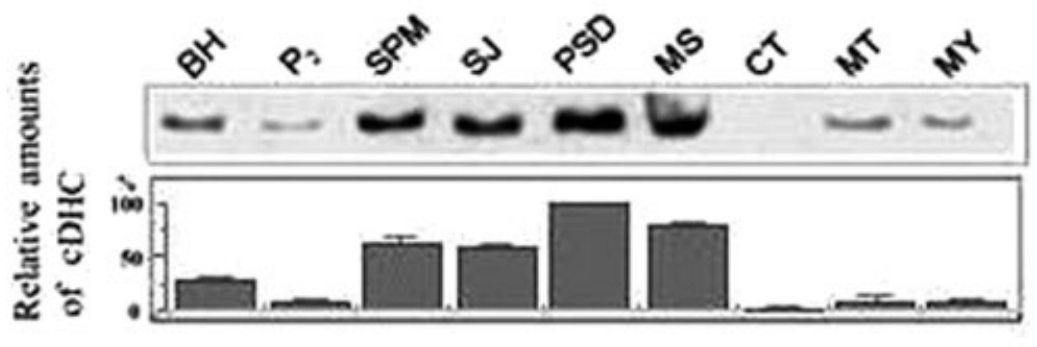

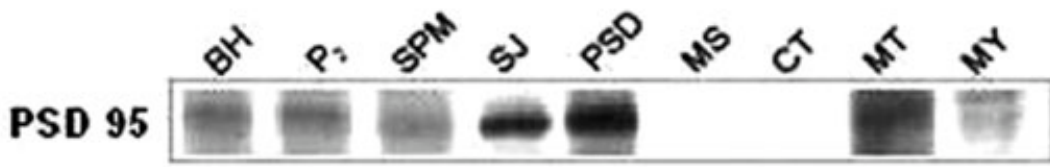

\section{Synaptophysin}

Syntaxin
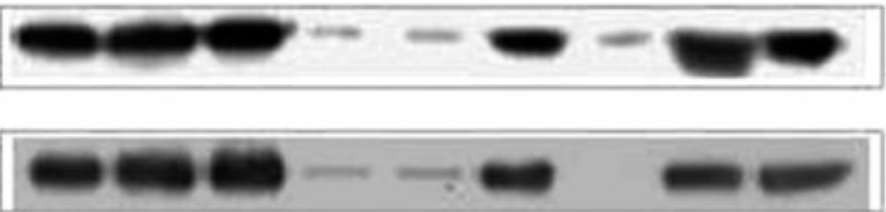

light chain is able to bind myosin $\mathrm{V}$ and guanylate kinase domain-associated protein (Naisbitt et al., 2000), and these latter proteins have also been identified in the PSD ( $\mathrm{Li}$ et al., 2004; Peng et al., 2004). cDHC contains domains that could bind microtubules (Koonce and Tikhonenko, 2000). Therefore, if the heavy, intermediate, and light chains of dynein in the PSD could assemble into a complex, this complex is likely to be linked to microfilament and microfilament-associated proteins via its light chain subunits and linked to $\alpha, \beta$-tubulins and various microtubule-associated proteins via its heavy chains. It is speculated that dynein may play a role or roles in the organization of the structure of the PSD.

Although not detected by most electron microscopic studies (Harris and Kater, 1994; Fiala et al., 2003), several reports have indicated that microtubules do appear in the branched spines in rat hippocampal CA3 region (Chicurel and Harris, 1992), or in brain tis- 

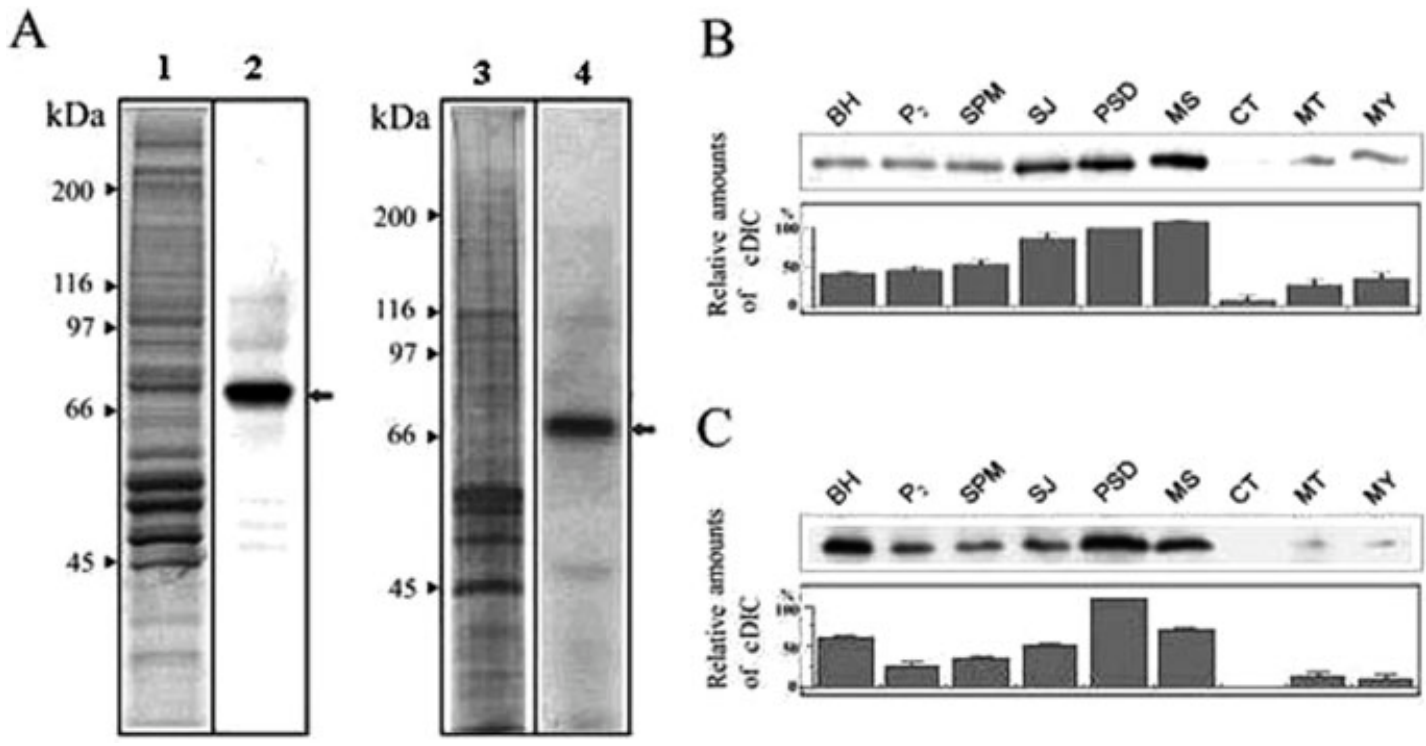

Fig. 7. Detection of cDIC in the PSD and other subcellular fractions isolated from porcine cerebral cortices and rat forebrains. A: Porcine cerebral cortical PSD (10 $\mu \mathrm{g}$ protein) and rat forebrain PSD $(10 \mu \mathrm{g}$ protein) were separated by $9 \%$ SDS-gel, transferred to PVDF membranes and then ProtoGold-stained (lanes 1, 3, respectively) or immunostained with antibody to CDIC (lanes 2, 4, respectively). The arrows on the left are the molecular weight markers. B,C top panels: Crude homogenate and 8 subcellular fraction samples, each containing $10 \mu \mathrm{g}$

protein, isolated from porcine cerebral cortices and rat forebrains, respectively, were subjected to Western blotting with the anti-cDIC antibody. B,C bottom panels: the immunostained bands in the top panels were quantified, and the amounts in various fractions were shown in values (mean $\pm \mathrm{SD}, n=4$ ) relative to those in the PSD fractions. $\mathrm{BH}$, brain homogenates; SPM, synaptic plasma membrane; SJ, synaptic junction; MS, microsome; PSD, postsynaptic density; CT, cytosol; MT, mitochondria; MY, myelin sheath.

sues after special treatment (Westrum and Gray, 1976, 1977; Westrum et al., 1980; Gray et al., 1982), or in hippocampal slices during the warming up process (Fiala et al., 2003). These observations raise the possibility that labile microtubules may transiently appear in the cytoplasm of dendritic spines under certain circumstances. Cytoplasmic dynein residing in the cortex regions has been reported to play important roles in many dynamic aspects of the cell, such as the organization and nucleation of microtubule cytoskeleton in interphase (Nedelec et al., 2003), mitotic spindle orientation, cytoskeleton reorientation and nuclear membrane breakdown during mitosis (Dujardin and Vallee, 2002; Salina et al., 2002), neuronal migration during development (Feng and Walsh, 2001) and tethering microtubules to adherens junctions at developing contacts between cells (Ligon et al., 2001). Therefore, by analogy, the microtubules that may transiently appear in the cytoplasm of dendritic spines would interact with dynein there and then induce certain local dynamic changes, such as the structural alterations of the spine as proposed by van Rossum and Hanisch (1999).

The enrichment of the major subunits of cytoplasmic dynein, a microtubule-associated protein motor complex, in the isolated PSD fraction and the presence of cDHC in dendritic spines raise new perspectives on the molecular mechanisms regulating the structure and function of the postsynaptic terminals in the brain. More effort is therefore needed in the future to investigate if

cytoplasmic dynein participates in the intracellular trafficking of various materials in the postsynaptic terminals, in the organization of the PSD structure and in the dynamic properties of dendritic spines.

\section{REFERENCES}

Baron MK, Boeckers TM, Vaida B, Faham S, Gingery M, Sawaya MR, Salyer D, Gundelfinger ED, Bowie JU. 2006. An architectural framework that may lie at the core of the postsynaptic density. Science 311: 531-535.

Brewer GJ, Torricelli JR, Evege EK, Price PJ. 1993. Optimized survival of hippocampal neuron in B27-supplemented Neurobasal, a new serum-free medium combination. J Neurosci Res 35:567-576.

Chang YC, Gottlieb DI. 1988. Characterization of the proteins purified with monoclonal antibodies to glutamic acid decarboxylase. J Neurosci 8:2123-2130.

Chang YC, Lin YH, Lee YH, Leng CH. 1991. Solubilization, characterization, and partial purification of $\alpha$-amino-3-hydroxy-5-methyl-4isoxazolepropionic acid, quisqualate-, kainate-sensitive L-glutamate binding sites from porcine brain synaptic junctions. J Neurochem 57: 1921-1926.

Chicurel ME, Harris KM. 1992. Three-dimensional analysis of the structure and composition of CA3 branched dendritic spines and their synaptic relationships with mossy fiber boutons in the rat hippocampus. J Comp Neurol 325:169-182.

Cohen RS, Blomberg F, Berzins K, Siekevitz P. 1977. The structure of postsynaptic densities isolated from dog cerebral cortex. I. Overall Morphology and Protein Composition. J Cell Biol 74:181-203.

Cho KO, Hunt CA, Kennedy MB. 1992. The rat brain postsynaptic density fraction contains a homolog of the Drosophila disc-large tumor suppressor protein. Neuron 9:929-942. 
Chuang JZ, Milner TA, Sung CH. 2001. Subunit heterogeneity of cytoplasmic dynein: Differential expression of $14 \mathrm{kDa}$ dynein light chains in rat hippocampus. J Neurosci 21:5501-5512.

Dosemeci A, Tao-Cheng JH, Vinade L, Winters CA, Pozzo-Miller L, Reese TS. 2001. Glutamate-induced transient modification of the postsynaptic density. Proc. Natl Acad Sci USA 98:10428-10432.

Dujardin DL, Vallee RB. 2002. Dynein at the cortex. Curr Opin Cell Biol 14:44-49.

Edwards FA. 1995. LTP: a structural model to explain the inconsistencies. Trends Neurosci 18:250-255.

Ehlers MD. 2003. Activity level controls postsynaptic composition and signaling via the ubiquitin-proteasome system. Nat Neurosci 6:231242.

Feng Y, Walsh C. 2001. Protein-protein interactions, cytoskeletal regulation and neuronal migration. Nat Rev Neurosci 2:408-416.

Fiala JC, Kirov SA, Feinberg MD, Petrak LJ, George PP, Goddard CA, Harris KM. 2003. Timing of neuronal and glial ultrastructure disruption during brain slice preparation and recovery in vitro. J Comp Neurol 465:90-103.

Fletcher TL, Cameron P, De Camilli P, Banker G. 1991. The distribution of synapsin I and synaptophysin in hippocampal neurons developing in culture. J Neurosci 11:1617-1626.

Gray EG, Westrum LE, Burgoyne RD, Barron J. 1982. Synaptic organization and neuron microtubule distribution. Cell Tissue Res 226:579588.

Harris KM, Kater SB. 1994. Dendritic spines: cellular specializations imparting both stability and flexibility to synaptic function. Annu Rev Neurosci 17:341-371.

Hata Y, Slaughter CA, Sudhof TC. 1993. Synaptic vesicle fusion complex contains unc-18 homologue bound to syntaxin. Nature 366:347351.

Holleran EA, Karki S, Holzbaur ELF. 1998. The role of the dynactin complex in intracellular motility. Int Rev Cytol 182:69-109.

Jordan BA, Fernholz BD, Boussac M, Xu C, Grigorean G, Ziff ED, Neubert TA. 2004. Identification and verification of novel rodent postsynaptic density proteins. Mol Cell Proteomics 3:857-871.

Kennedy MB. 1997. The postsynaptic density at glutamatergic synapses. Trends Neurosci 20:264-268.

Kennedy MB. 2000. Signal-processing machines at the postsynaptic density. Science 290:750-754.

Koonce MP, Tikhonenko I. 2000. Functional elements within the dynein microtubule-binding domain. Mol Biol Cell 11:523-529.

Laemmli UK. 1970. Cleavage of structural proteins during the assembly of the head of bacteriophage T4. Nature 227:680-685.

Lai SL, Ling SC, Kuo LH, Shu YC, Chow WY, Chang YC. 1998. Characterization of granular particles isolated from postsynaptic densities. J Neurochem 71:1694-1701.

Lai SL, Chiang SF, Chen IT, Chow WY, Chang YC. 1999. Interprotein disulfide bonds formed during isolation process tighten the structure of the postsynaptic density. J Neurochem 73:2130-2138.

Li KW, Hornshaw MP, Van Der Schors RC, Watson R, Tate S, Casetta B, Jimenez CR, Gouwenberg Y, Gundelfinger ED, Smalla KH, Smit AB. 2004. Proteomics analysis of rat brain postsynaptic density. Implications of the diverse protein functional groups for the integration of synaptic physiology. J Biol Chem 279:987-1002.

Ligon LA, Karki S, Tokito M, Holzbaur EL. 2001. Dynein binds to $\beta$ catenin and may tether microtubules at adherens junctions. Nat Cell Biol 3:913-917.

Lisman JE, Harris KM. 1993. Quantal analysis and synaptic anatomy-integrating two views of hippocampal plasticity. Trends Neurosci 16:141147.

Lisman J, Schulman H, Cline H. 2002. The molecular basis of CaMK II function in synaptic and behavioral memory. Nat Rev Neurosci 3:175190.
Lowry OH, Rosebrough NJ, Farr AL, Randall RJ. 1951. Protein measurement with the Folin phenol reagent. J Biol Chem 193:265-275.

Luscher C, Nicoll RA, Malenka RC, Muller D. 2000. Synaptic plasticity and dynamic modulation of the postsynaptic membrane. Nat Neurosci 3:545-550.

Marrs GS, Green SH, Dailey ME. 2001. Rapid formation and remodeling of postsynaptic densities in developing dendrites. Nat Neurosci 4: 1006-1013.

Murthy VN, Schikorski T, Stevens CF, Zhu Y. 2001. Inactivity produces increases in neurotransmitter release and synapse size. Neuron 32:673682

Naisbitt S, Valtschanoff J, Allison DW, Sala C, Kim E, Craig AM, Weinberg RJ, Sheng M. 2000. Interaction of the postsynaptic density-95/ guanylate kinase domain-associated protein complex with a light chain of myosin- $\mathrm{V}$ and dynein. J Neurosci 20:4524-4534.

Nedelec F, Surrey T, Karsenti E. 2003. Self-organization and forces in the microtubule cytoskeleton. Curr Opin Cell Biol 15:118-124.

Paschal BM, Mikami A, Pfister KK, Vallee RB. 1992. Homology of the 74-kD cytoplasmic dynein subunit with a flagellar dynein polypeptide suggests an intracellular targeting function. J Cell Biol 118:1133-1143.

Peng J, Kim MJ, Cheng D, Duong DM, Gygi SP, Sheng M. 2004. Semi-quantitative proteomic analysis of rat forebrain postsynaptic density fractions by mass spectrometry. J Biol Chem 279:21003-21011.

Peters A, Palay SL, Webster HDF. 1991. The fine structure of the nervous system: neurons and their supporting cells. New York: Oxford University Press. p 138-211.

Peterson BS. 2003. Brain imaging studies of the anatomical and functional consequences of preterm birth for human brain development. Ann NY Acad Sci 1008:219-237.

Salina D, Bodoor K, Eckley DM, Schroer T, Rattner JB, Burke B. 2002. Cytoplasmic dynein as a facilitator of nuclear envelop breakdown. Cell 108:97-107.

Satoh K, Takeuchi M, Oda Y, Deguchi-Tawarada M, Sakamoto Y, Matsubara K, Nagasu T, Takai Y. 2002. Identification of activity-regulated proteins in the postsynaptic density fraction. Genes Cells 7:187-197.

Sheng M, Sala C. 2001. PDZ domains and the organization of supramolecular complexes. Annu Rev Neurosci 24:1-29.

Shevchenko A, Wilm M, Vorm O, Mann M. 1996. Mass spectrometric sequencing of proteins from silver-stained polyacrylamide gels. Anal Chem 68:850-858.

Siekevitz P. 1985. The postsynaptic density: a possible role in long-lasting effects in the central nervous system. Proc Natl Acad Sci USA 82: 3494-3498.

Steffen W, Hodgkinson JL, Wiche G. 1996. Immunogold localization of the intermediate chain within the protein complex of cytoplasmic dynein. J Struct Biol 117:227-235.

Sui CW, Chow WY, Chang YC. 2000. Effects of disulfide bonds formed during isolation process on the structure of the postsynaptic density. Brain Res 873:268-273.

Toni N, Buchs PA, Nikonenko I, Bron CR, Muller D. 1999. LTP promotes formation of multiple spine synapses between a single axon terminal and a dendrite. Nature 402:421-425.

Toni N, Buchs PA, Nikonenko I, Povilaitite P, Parisi L, Muller D. 2001. Remodeling of synaptic membranes after induction of long-term potentiation. J Neurosci 21:6245-6251.

Valtschanoff JG, Weinberg RJ. 2001. Laminar organization of the NMDA receptor complex within the postsynaptic density. J Neurosci 21: 1211-1217.

Van Rossum D, Hanisch UK. 1999. Cytoskeletal dynamics in dendritic spines: direct modulation by glutamate receptors? Trends Neurosci 22:290-295.

Walikonis RS, Jensen ON, Mann M, Provance DW Jr, Mercer JA, Kennedy MB. 2000. Identification of proteins in the postsynaptic density fraction by mass spectrometry. J Neurosci 20:4069-4080. 
Walsh MJ, Kuruc N. 1992. The postsynaptic density: constituent and associated proteins characterized by electrophoresis, immunoblotting, and peptide sequencing. J Neurochem 59:667-678.

Weber K, Osborn M. 1969. The Reliability of molecular weight determinations by dodecyl sulfate-polyacrylamide gel electrophoresis. J Biol Chem 244:4406-4412.

Westrum LE, Gray EG. 1976. Microtubules and membrane specializations. Brain Res 105:547-550.

Westrum LE, Gray EG. 1977. Microtubules associated with postsynaptic thickenings. J Neurocytol 6:505-518.

Westrum LE, Jones DH, Gray EG, Barron J. 1980. Microtubules, dendritic spines and spine apparatuses. Cell Tissue Res 208:171-181.
Wu TY, Liu CI, Chang YC. 1996. A study of the oligomeric state of the $\alpha$-amino-3-hydroxy-5-methyl-4-isoxazolepropionic acid-preferring glutamate receptors in the synaptic junctions of porcine brain. Biochem J 319:731-739.

Yoshimura Y, Yamauchi Y, Shinkawa T, Taoka M, Donai H, Takahashi N, Isobe T, Yamauchi T. 2004. Molecular constituents of the postsynaptic density fraction revealed by proteomic analysis using multidimensional liquid chromatography-tandem mass spectrometry. J Neurochem 88:759-768.

Yu H, Toyoshima I, Steuer ER, Sheetz MP. 1992. Kinesin and cytoplasmic dynein binding to brain microsomes. J Biol Chem 267:20457-20464.

Ziff EB. 1997. Enlightening the postsynaptic density. Neuron 19:11631174. 